\title{
Tumor necrosis factor alpha gene level in patients with tympanosclerosis M.F.Shendy ${ }^{1}$, Y.M.Mandour ${ }^{1}$, S.A.Mohammed ${ }^{2}$, A.H.El-zobeir ${ }^{1}$ and A.Abdel-aal ${ }^{1}$ \\ ${ }^{1}$ Otorhinolaryngology, Dept., Faculty of Medicine, Benha Univ., Benha, Egypt \\ ${ }^{2}$ Medical Biochemistry \& Molecuolar Biology, Dept., Faculty of Medicine, Benha Univ., Benha, Egypt \\ Email:ahmedelzobeir@gmail.com
}

\begin{abstract}
Background: Tympanosclerosis is the calcification of connective tissue in the middle ear, particularly the tympanic membrane, which can arise following middle ear infection. Inflammatory reactions are induced and maintained by tumour necrosis factor (TNF) in a variety of illnesses, including chronic otitis media with effusion (COME). The goal of this study was to determine the plasma level of Tumer necrosis factor (TNF) gene expression in individuals who had tympanosclerosis as a result of ventilation tube insertion. Methods: This study comprised sixty patients who were separated into two groups: 60 patients were assigned to Group A based on inclusion and exclusion criteria, whereas 20 volunteers were assigned to Group B. Patients were given a medical history, a thorough physical examination, and a TNF- gene expression test in the lab (qRT-PCR). Results: There was a significant difference in TNF-gene expression across groups, with the mean TNF in the cases group (3.87) being significantly greater than the control group (1), p0.001. TNF levels were statistically different depending on the number of tubes inserted $(\mathrm{p}=0.005)$ and the time of secretory $\mathrm{OM}(\mathrm{p}=0.042)$. There was no significant difference in TNF levels when it came to medication usage or acute OM episodes. Conclusion: TNF- gene profile expression was statistically significant higher in selected middle-ear structures with tympanosclerosis than in the control group.
\end{abstract}

Keywords: Tumor necrosis factor alpha, TNF- $\alpha$, otitis media, OM, quantitative real time PCR, QRT-PCR, polymerase chain reaction,PCR. chronic otitis media with effusion, COME.

\section{Introduction}

The calcification of middle ear connective tissue, including the tympanic membrane, that develops following middle ear inflammation is known as tympanosclerosis. At first, tympanosclerosis appears as a cheese-like mass of sclerotic material that grows firmer and later turns into bone-like substance [1].

The steady deposition of hyaline material across the tympanic membrane, as well as inflammatory hypertrophic submucosa in the middle ear cavity, characterises tympanosclerosis. Mobilization is hampered by calcification of the tympanic membranes and ossicles [2].

Infection, inflammation, or trauma involving any degree of local immunological hypersensitivity activates the connective tissue part of these structures, according to the pathophysiology theory for tympanosclerosis. The inner surface of the drum exhibits more permeable mucosal changes with a severe middle ear infection, and the lamina propria is edematous ground material soaking up water and middle ear illness components. The presence of immunoglobulin components in irregular middle ear secretions enables it to participate in the process. If the connective tissue is damaged, adsorption and repair aid the body's immune response to the injured tissue, sensitising this area [3].

A submucosal response evidenced by collagen deposition occurs after each episode of chronic middle ear effusion. As a result, the distinctive lamellated plaque structure may be described as numerous onion layers, with each "onion sheet" representing each episode of middle ear effusion and its associated fibrogenesis, and characterising the lamellated structure of tympanosclerotic plaques [4].

Tumor necrosis factor (TNF) seems to be important in generating and sustaining inflammatory response in a variety of diseases, including chronic otitis media with effusion (COME). Cytokine inhibitors have recently been discovered to control the proinflammatory effects of certain cytokines. This led us to believe that COME's prolonged inflammation was caused by a mismatch between proinflammatory cytokines and inhibitors, with proinflammatory cytokines outnumbering inhibitors [5].

TNF is a cytokine generated by macrophages in response to stimuli such as bacterial endotoxin and viruses. This cytokine is also produced by mast cells, which are a major source. It has also been established that (TNF) $\alpha$ promotes the production of histamine by human basophiles and mast cells. IgE-dependent stimulation of mast cells generates rapid extracellular release from preformed (TNF) $\alpha$ with histamine and proteoglycans and increased mRNA (TNF) $\alpha$. [6].

ELISA was extensively employed for cytokine concentration calculations. MEE cytokines have been accurately identified using ELISA responsive sandwich. Results indicated significant increases in the positive community of allergies (TNF) $\alpha$. In MEEs, TNF-a may contribute to OME's allergic persistence [7].

This study tested $\alpha$-gene expression in Tumer Necrosis Factor (TNF) in tympanosclerosis patients owing to the insertion of the ventilating tube.

\section{Patients and methods}

Sixty patients and 20 volunteers were included in this prospective randomised controlled research. All patients have been chosen from the Benha University Hospital ORL clinic. The research was authorised by the Faculty of Medicine's ethical center at the University of Benha. All subjects signed informed consents.

Group A: 60 patients according to the inclusion and exclusion criteria, and Group B:20 voluntary people 
without a history of any ear illness and with no other systemic illnesses as evident health controls. Patients were separated into two groups.

\subsection{Inclusion criteria}

- Patients age were between 3 to 15 years old

- Persistent MEE for 3 months.

- History of acute otitis media in the preceding 3 months.

- History of multiple placements of tympanostomy tubes.

\subsection{Exclusion criteria}

- Systemic diseases.

- Acute upper respiratory tract infection.

- Craniofacial anomalies.

- Patients were subjected to history taking, full clinical examination and laboratory investigation of TNF- $\alpha$ gene expression

\subsection{Sampling}

A venous blood sample $(2 \mathrm{ml})$ was taken from each subject \& put into plain sterile vaccutainer tube , blood will be left to clot and then centrifuged at $3000 \mathrm{rpm}$, serum was separated and put into sterile eppendorff tubes and refrigerated at $-80^{\circ} \mathrm{C}$ till the time of RNA extraction.

Quantitation of TNF- $\alpha$ gene expression: TNF- $\alpha$ gene expression was measured by quantitative real-time PCR (qRT-PCR) through the following steps:

1. Total mRNA extraction from 100 ul serum by Total RNA Purification Kit (Jena Bioscience, Germany), as per manufacturer's instructions. Nanodrop 2000 Spectrophotometer (Thermo Fisher Scientific, Wilmington, USA) performed RNA ultraviolet spectrophotometric quantification. Pure RNA preparations have 1.9-2.3 optical density ratio at 260/280 nm [8].

2. qRT-PCR for TNF on 2 steps:

1. The first step (reverse transcription of RNA into cDNA):

It was performed by Hisenscript RH (-) cDNA synthesis kit (Intron Biotechnology, Korea) using Veriti $^{\mathrm{TM}}$ Thermal Cycler (Applied Biosystems, USA). The reverse transcription (RT) mix for each sample contained 2X RT reaction solution (10 ul), enzyme solution ( $1 \mathrm{ul})$, RNA template $(2 \mathrm{ul})$ and nuclease-free water $(7 \mathrm{ul})$. Incubation of RT mix at $45^{\circ} \mathrm{C}$ for 1 hour was performed, followed by RTase inactivation at $85^{\circ} \mathrm{C}$ for $10 \mathrm{~min}$.
2. second step (quantitation of TNF mRNA using specific primers): use of Stepone real-time PCR (Applied Biosystem, Singapore). Singleplex reactions occurred. Hera plus Sybr Green qPCR master mix (Life Technologies Corporation, UK). Human GAPDH was the housekeeping gene..

THE PRIMERS WERE AS FOLLOW: TNF-A; FP: 5'-CCCAGGCAGTCAGATCATCTTC-3', RP: 5'AGCTGCCCCTCAGCTTGA-3', GAPDH; FP: TGAACGGGAAGCTCACTGG AND RP: TCCACCACCCTGTTGCTGTA [9].

The master mix for qRT-PCR contained $10 \mathrm{ul}$ master mix, 1 ul FP, 1 ul RP 2 ul cDNA and 6 ul nuclease-free water. The thermal cycling conditions were: initial denaturation at $95^{\circ} \mathrm{C}$ for $2 \mathrm{~min}$. and cycling (45 cycles) that includes denaturation at $95^{\circ} \mathrm{C}$ for $30 \mathrm{sec}$. and annealing / extension at $60^{\circ} \mathrm{C}$ for $30 \mathrm{~min}$. Melting curve analysis was done in each run to confirm specificity of the reaction.

\subsection{Statistical analysis}

A report type reported clinical results. These results were tabulated and evaluated using the SPSS (Statistical Kit for Social Science) version 20 to obtain: for the data, descriptive statistics were measured in the form of: mean and standard deviation, median and inter-quartile range (IQR) for quantitative data. Frequency and qualitative data delivery. Analytical statistics: In statistical comparison of various categories, the value of variance was checked using one of the following tests, Student's ttest:- Used to equate mean of two quantitative data groups. ANOVA measure (F value):-Compare mean of more than two quantitative data classes. The intergroup analysis of categorical data was conducted using chi square (X2-value) and Fishery Exact (FET) measures. Correlation coefficient:- finding relationships among variables. Statistically important was a $\mathrm{P}$-value $<0.05$.

\section{Results}

In this study, Patients were divided into 2 groups: Group A: 60 patients, according to inclusion and exclusion criteria. Group B: 20 volunteers, with no history of any previous ear diseases and no any other systemic diseases as apparent healthy controls. There was no statistical difference between cases and controls regarding to their age or gender.

According to TNF- $\alpha$ gene expression; there was a statistical difference between groups; as the mean TNF in cases group (3.87) was statistically higher than control group (1), p<0.001. Fig. (1).

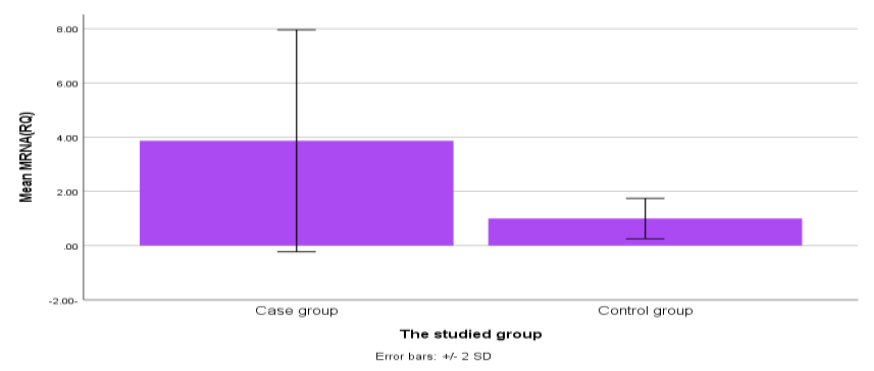

Fig. (1) Comparison between case and control groups according to TNF- $\alpha$ gene expression MRNA (RQ). 


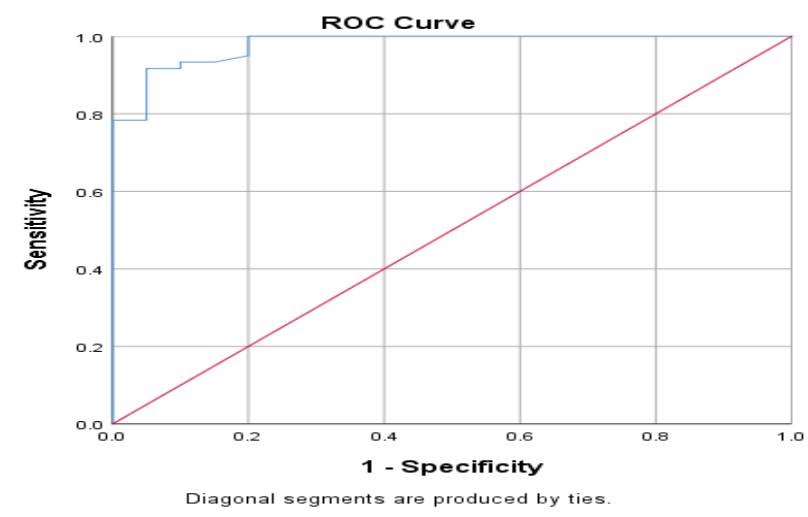

Fig. (2) ROC curve of validity of TNF- $\alpha$ MRNA (RQ) in detection of cases

Table (1) Comparison between TNF- $\alpha$ MRNA (RQ) level in otitis media cases according to their medical history.

\begin{tabular}{|c|c|c|c|c|c|}
\hline & \multirow[t]{2}{*}{ No (60) } & \multicolumn{2}{|c|}{ TNF- $\alpha$ MRNA (RQ) } & \multirow[t]{2}{*}{ Statistical test } & \multirow[t]{2}{*}{ P value } \\
\hline & & Mean & $\pm \mathrm{SD}$ & & \\
\hline \multicolumn{6}{|c|}{ Medication use (Antibiotics) } \\
\hline Yes & 29 & 4.51 & 1.73 & $\mathrm{St} \mathrm{t}=1.33$ & 0.19 \\
\hline No & 31 & 3.51 & 2.28 & & \\
\hline \multicolumn{6}{|c|}{ Number of tube insertion } \\
\hline One & 37 & 4.79 & 1.96 & St $t=2.91$ & $0.005^{* *}$ \\
\hline More than one & 23 & 3.30 & 1.91 & & \\
\hline \multicolumn{6}{|c|}{ Episodes of acute OM } \\
\hline Once & 16 & 4.32 & 2.36 & $\mathrm{~F}=2.43$ & 0.097 \\
\hline Twice & 7 & 5.05 & 2.0 & & \\
\hline None & 37 & 3.45 & 1.83 & & \\
\hline \multicolumn{6}{|c|}{ Duration of secretory OM } \\
\hline 3 months & 37 & 4.47 & 1.77 & St $\mathrm{t}=1.99$ & $0.042 *$ \\
\hline$>3$ months & 23 & 3.52 & 2.32 & & \\
\hline
\end{tabular}

St t: student t-test; F: one way anova; *: significant; **: highly significant; OM: otitis media TNF- $\alpha$ : tumor necrotic factor-alpha; MRNA: messenger RNA; RQ: relative quantitation.

Table (2) Correlation between TNF- $\alpha$ MRNA (RQ) and medical history of the studied OM cases.

\begin{tabular}{lll}
\hline TNF- $\alpha$ MRNA (RQ) & Correlation coefficient & P value \\
\hline Medication use (Antibiotics) & 0.281 & $0.03^{*}$ \\
Number of tube insertion & -0.436 & $<0.001^{* *}$ \\
Episodes of acute OM & 0.28 & $0.03^{*}$ \\
Duration of secretory OM & 0.252 & 0.052 \\
\hline
\end{tabular}

*: significant; **: highly significant; OM: otitis media TNF- $\alpha$ : tumor necrotic factor-alpha; MRNA: messenger RNA; RQ: relative quantitation.

ROC curve was done to assess the validity of TNF- $\alpha$ MRNA (RQ) in detection of cases; AUC was 0.979 (CI: 0.952-1.0), at a cutoff value of 1.33; Sensitivity was 100 , specificity was 80 , PPV was 93.8, NPV was 100, and Accuracy was $95 \%$. Fig. (2).

There was statistical difference in TNF level regarding to number of tube insertion $(\mathrm{p}=0.005)$ and duration of secretory $\mathrm{OM}(\mathrm{p}=0.042)$. While there was no statistical difference in TNF level regarding medication use or episodes of acute OM. Table (1).

There was a significant positive correlation between TNF and (Medication use and Episodes of acute OM) and there was a significant negative correlation between
TNF and number of tube insertion. While there was no significant correlation between $\mathrm{TNF}$ and duration of secretory OM. Table (2).

\section{Discussion}

The research indicated statistically significant, increased (TNF) $\alpha$ Proinflammatory cytokine gene transcriptions in plasma samples from tympanosclerosis patients, as compared to the control group.

These findings correlate with Mionskowski etc. [6], who showed that Total RNA has been extracted with modifications of its own from tissues in accordance with the Chomczyński and Sachcci methods. Isolated RNA 
was used in real time as a template in One Step Multiplex PCR using Taq Man samples. The transcript level ratio of the TNF $\alpha$ gene to the reference gene transcript level (b-actin) was measured for the mRNA level. TNF $\alpha$ gene expression was much greater in tympanic membranes from patients with tympanosclerosis than in middle ear mucous and tympanic membranes from the cadaver $(p=0.00001)$. The median value of TNF $\alpha$ in the control group was 1.41 and 24.78 in the study group.

Maxwell et al., [10] remarked that Age was examined periodically and showed no statistically significant $\mathrm{TNF} \alpha$ relation $(\mathrm{P}=.46)$. Tumor necrosis factor has been shown to be significantly less than the recurrence of tube placements increased $(\mathrm{p}=.008)$, and variances remained significant in nominal assessment $(\mathrm{p}=.02$; total protein $3.87 \pm 0.31 \mathrm{pg} / \mathrm{mg}$ for first tympanostomy vs $2.66 \pm 0.41 \mathrm{pg} / \mathrm{mg}$ for preceded tympanostomy). Drug use has been nominally explored. Tumor necrosis factor rose with history of antibiotics but was not significantly different from children who did not get peri-operative medications. With antibiotic history, TNFsolR looked to be elevated, but no significant variance in TNFsol $\mathrm{R}$ was computed based on perioperative antibiotic usage.

Other studies, such as Alpay H C et al. [11], have demonstrated that TLR4 gene variation genotype has a role in the inflammatory process, minimising the expresses IL-6, IL-10 or TNF $\alpha$ cytokine. The reduced expressions of these cytokines generate systemic inflammation, which leads to the macrophage's longterm transition into osteoclasts that may cause TSP.

According to Yellon et al. [12] the mean TNF- $\alpha$ levels of the children with recurrent tympanostomy are around 14 times higher than those of the children with their first tympanostomy. For IL- $1 \beta$ and IL-6, the similar relationship was seen.

However, there were no significant correlations in MEE between the total of prior insertions of the tube and the amounts of TNF- $\alpha$ and IL- $1 \beta$ observed by Willett et al. [13].

The marginal statistic significance of interaction between TNF- $\alpha$ and IL- 8 was discovered by Skotnicka et al. [14] $(r=0,31 ; P=0,056)$. However, no link with IL-10 and other cytokines studied was detected. The association was not established between age, hearing loss length, number of acute otitis media episodes and cytokine levels. No statistically significant connection between tympanic membrane disease and cytokine levels was discovered during otoscopic examinations.

\section{Conclusion}

The level of gene profile expression for TNF- $\alpha$ in selected structures of the middle ear with tympanosclerosis was statistically significant, higher in comparison with the control group.

\subsection{Sources of funding}

This research obtained no particular grant from state, commercial or non-profit funding agencies.

\subsection{Author contribution}

Authors contributed equally in the study.

\subsection{Conflicts of interest}

No conflicts of interest

\section{References}

[1] T.Karldağ, N.İlhan, İ.Kaygusuz, E.Keleş, Ş.Yalçn. Comparison of free radicals and antioxidant enzymes in chronic otitis media with and without tympanosclerosis. Laryngoscope.vol.114(1),pp.859,2004.

[2] A.Trojanowska, A.Drop, P.Trojanowski, RosińskaBogusiewicz K, Klatka J, Bobek-Billewicz B. External and middle ear diseases: radiological diagnosis based on clinical signs and symptoms. Insights Imaging.vol.3(1),pp.33-48,2012.

[3] KR.Magliocca, EX.Vivas, CC.Griffith. Idiopathic, infectious and reactive lesions of the ear and temporal bone. Head Neck Pathol.vol.12(3),pp.328-49,2018.

[4] G.Aynali, M.Yariktaş, H.Yasan, N.Karahan, Ş.Başpinar, M.Tüz. The effects of methylprednisolone, montelukast and indomethacine in experimental otitis media with effusion. Int J Otorhinolaryngol.vol.75(1),pp.15-9,2011.

[5] LB.Silva, AP.dos Santos Neto, SMAS.Maia, C.dos Santos Guimarães, IL.Quidute, A. Carvalho de AT. The Role of TNF- $\alpha$ as a Proinflammatory Cytokine in Pathological Processes. Open Dent J.vol.13.pp.(1),2019.

[6] T.Mionskowski, J.Kuczkowski, M.SakowiczBurkiewicz. Assessment of tumor necrosis factor alpha gene expression profile in selected structures of middle ear in patients with tympanosclerosis. Otolaryngol Pol Polish Otolaryngol.vol.66(4 Suppl),pp.20-4,2012.

[7] CH.Jang. Characterization of Cytokines Present in Pediatric Recurrent Otitis Media with Effusion: Comparison of Allergy and Nonallergy. Korean J Otorhinolaryngol Neck Surg.vol.43(8),pp.80812,2000 .

[8] WW.Wilfinger, K.Mackey, P.Chomczynski. Effect of $\mathrm{pH}$ and ionic strength on the spectrophotometric assessment of nucleic acid purity. Biotechniques.vol.22(3),pp.474-81,1997.

[9] S.Park Bin, BC.Jee, SH.Kim, YJ.Cho, M.Han. Cyclooxygenase-2 inhibitor, celecoxib, inhibits leiomyoma cell proliferation through the nuclear factor $\kappa \mathrm{B}$ pathway. Reprod Sci.vol.21(9),pp.118795,2014.

[10] K.Maxwell, G.Leonard, DL.Kreutzer. Cytokine expression in otitis media with effusion: tumor necrosis factor soluble receptor. Arch Otolaryngol Neck Surg.vol.123(9),pp.984-8,1997.

[11]HC.Alpay, EO.Etem, I.Kaygusuz, H.Yüce, T.Karlidag, E.Keles. Evaluation of the polymorphism in the Toll-like receptor 4 (TLR4) 
genes of tympanosclerosis patients. Auris Nasus Larynx.vol.37(1),pp.29-32,2010.

[12] RF.Yellon, WJ.Doyle, TL.Whiteside, WF.Diven, AR, March, P.Fireman. Cytokines, immunoglobulins, and bacterial pathogens in middle ear effusions. Arch Otolaryngol Neck Surg.vol.121(8),pp.865-9,1995.

[13]DN.Willett, RP.Rezaee, JM.Billy, MB.Tighe, TF.DeMaria. Relationship of endotoxin to tumor necrosis factor $-\alpha$ and interleukin- $1 \beta$ in children with otitis media with effusion. Ann Otol Rhinol Laryngol.vol.107(1),pp.28-33,1998.

[14]B.Skotnicka, E.Hassmann. Cytokines in children with otitis media with effusion. Eur Arch otorhino-laryngology.vol.257(6),pp.323-6,2000. 